\title{
Direct effect and spatial spillover effect of rural human capital on agricultural non-point source pollution
}

\author{
Hu H. ${ }^{1}$, Dai J. ${ }^{2 *}$, Zhang L. ${ }^{3}$, Wang X. ${ }^{4}$ and Ma Y. ${ }^{4}$ \\ ${ }^{1}$ School of Economics and Management, Beijing Information Science and Technology University, Beijing 100192, China \\ ${ }^{2}$ Business School, China University of Political Science and Law, Beijing, 100088, China \\ ${ }^{3}$ Department of Life Culture, Beijing College of Social Administration, Beijing 101601, China \\ ${ }^{4}$ School of Economics and Management, North China University of Technology, Beijing 100144, China \\ Received: 06/07/2020, Accepted: 09/08/2020, Available online: 22/10/2020 \\ *to whom all correspondence should be addressed: e-mail: daijianhua66@163.com
} https://doi.org/10.30955/gnj.003402

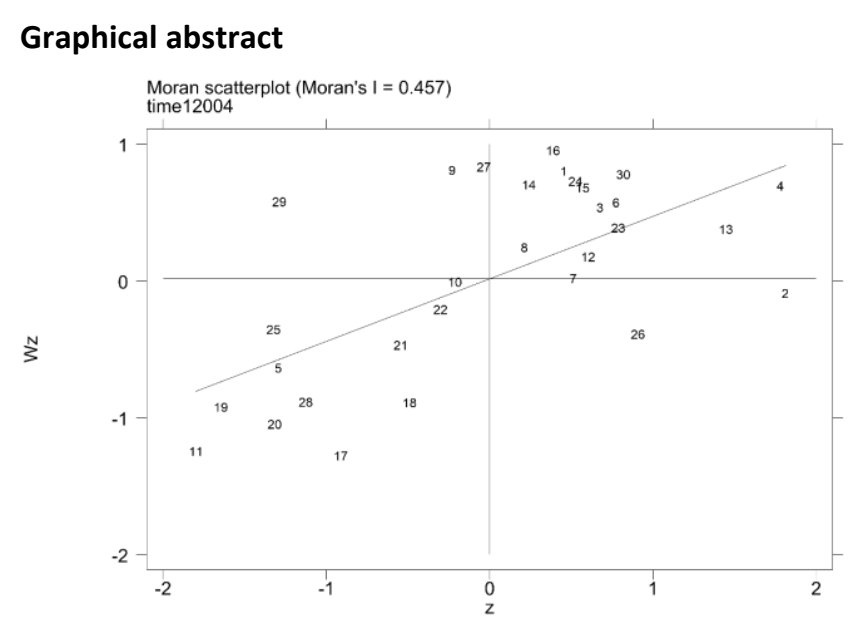

\begin{abstract}
With the increasingly prominent problem of agricultural non-point source pollution, the process of Rural Revitalization Strategy has been seriously affected. Studying the relationship between rural human capital and agricultural non-point source pollution is helpful to form talent bonus, improve rural ecological environment and realize the green development of agriculture. This paper takes 30 provinces and cities of China as the research object and uses Spatial Durbin model for empirical analysis. According to the research results, it is found that agricultural non-point source pollution has significant spatial correlation and the correlation presents a fluctuating trend; Rural human capital has obvious direct effect $(-0.678)$ and spatial spillover effect $(-0.707)$, which helps to alleviate agricultural non-point source pollution. After considering different forms of space matrix, the result is considered to be robust. The conclusion of this paper provides policy enlightenment for promoting the construction of rural human capital and improving the continuous development of rural ecological environment curriculum.
\end{abstract}

Keywords: Agricultural non-point source pollution, spatial spillover, spatial panel measurement, rural human capital.

\section{Introduction}

Although the 70 year development of China's rural economy has made an important contribution to the sustainable development of the whole national economy, it has also made a huge loss to the ecological environment. Although China has increased the treatment of pollution since the 17th National Congress of the Communist Party of China, agricultural non-point source pollution has become an obstacle to the realization of Rural Revitalization Strategy because of its characteristics of "scattered source, difficult to monitor and difficult to control". Compared with developed countries, China's agriculture has many problems, such as single development form, low technology content, easy to cause environmental pollution, serious abuse of pesticides and chemical fertilizers in the agricultural production process, and unreasonable utilization of agricultural waste resources, which all make agricultural non-point source pollution intensified. Control and prevention of agricultural non-point source pollution has become the primary task of rural work. Rural human capital, as an important part of agricultural production and management, is the first factor of production, which directly determines the quality of labor force and the mode of production and management. In this paper, the impact of rural human capital on agricultural non-point source pollution is discussed from the perspective of spatial spillover, in order to provide a reference for the government to alleviate agricultural nonpoint source pollution (Suhaili et al., 2018; Sajil et al., 2020; Swodesh et al., 2020; Humaira et al., 2018).

At present, there are many literatures about agricultural non-point source pollution, among which some scholars have studied the measurement (Lai et al., 2004; Qiu et al., 2018), influencing factors (You, 2016), formation mechanism (Lu and Wang, 2008), prevention and control measures (Bechmann et al., 2008) of agricultural non-point source pollution. The existing studies have adopted different methods to measure agricultural non-point source pollution, which not only provides an effective way 
to measure the current situation and evolution of agricultural non-point source pollution, but also simply reveals the reasons for the formation of regional agricultural non-point source pollution pattern in China (Okoli et al., 2018; Md. Nazmul et al., 2019; Faiza et al., 2018; Fikriah et al., 2019).

In addition, the relationship between external factors and agricultural non-point source pollution has been discussed by some scholars. For example, Xue et al. (2019) made an empirical study on the impact of urbanization on agricultural non-point source pollution; Xia et al. (2018) tried to build a theoretical analysis framework of the impact of farmers' part-time employment on agricultural non-point source pollution on the basis of fully considering the nature of farmers' dual identity, and used the rice planting experience of Hunan, Jiangxi and Jiangsu provinces as evidence for empirical test; Liang et al. (2018) analyzed the spatial interaction effect of agricultural nonpoint source pollution and agricultural economic growth by using spatial simultaneous equation model.

It can be seen that although experts and scholars have done a series of research on the increasingly serious agricultural non-point source pollution, there is a lack of research on the relationship between rural human capital and agricultural non-point source pollution. Therefore, in order to test the impact of rural human capital on agricultural non-point source pollution in China, this paper aims to study whether rural human capital has spatial spillover effect and whether it has different effects on the growth of surrounding areas. This paper studies the direct and indirect effects of rural human capital on agricultural non-point source pollution by using spatial econometric analysis technology, aiming to provide data support for the treatment of agricultural non-point source pollution in adjacent areas.

\section{Empirical methods and data sources}

\subsection{Test of spatial correlation}

Exploratory spatial analysis can test the existence of significant spatial distribution from a statistical point of view. At present, there are two commonly used analysis methods to measure spatial autocorrelation: global spatial autocorrelation and local autocorrelation, and two common analysis methods: Moran's I and Geary's C.

\subsubsection{Global spatial autocorrelation}

Global spatial autocorrelation is derived from covariance of statistical correlation coefficient.

$$
I=\frac{n}{\sum_{i=1}^{n} \sum_{j=1}^{n} W_{i j}} \times \frac{\sum_{i=1}^{n} \sum_{j=1}^{n} W_{i j}\left(x_{i}-\bar{x}\right)\left(x_{j}-\bar{x}\right)}{\sum_{i=1}^{n}\left(x_{i}-x\right)}
$$

In Equation (1), $i$ and $j$ of represent the $i$ th and $j$ th regions respectively. $W_{i j}$ is a spatial weight matrix, mainly including adjacency matrix, economic matrix and so on. This paper selects the spatial adjacency matrix, the adjacent area is assigned as 1 , otherwise it is 0 . The value range of $I$ is from -1 to 1 . The larger the absolute value of $I$ is, the stronger the correlation is. When $I>0$, it indicates that they are positively correlated. When $l<0$, it indicates that they are negatively correlated. When I approaches 0 , it indicates that they are not correlated.

\subsubsection{Local spatial autocorrelation}

Global spatial autocorrelation assumes that the space is homogeneous and studies the trend of the whole region. Local spatial autocorrelation is used to determine the specific aggregation area. Taking local Moran index as an example, the calculation formula is as follows:

$$
I_{i}=\frac{\left(Y_{j}-\bar{Y}\right) \sum_{j=1}^{n} W_{i j}\left(Y_{i}-\bar{Y}\right)}{S^{2}}
$$

$\left(Y_{i}-\bar{Y}\right)$ and $\left(Y_{j}-\bar{Y}\right)$ in Equation (2) represent the difference between $Y_{i}$ and the mean value and $Y_{j}$ and the mean value. When $I_{i}>0$, it indicates that there is local spatial agglomeration, and when $l_{i}<0$, it indicates that there is local spatial exclusion.

\subsection{Spatial panel measurement model}

Spatial panel measurement model has a variety of expressions, among which the more common ones are Spatial Error Model (SEM), Spatial Autoregressive Model (SAR), Spatial Lag Model (SLM) and Spatial Durbin Model (SDM). Among them, SDM model is the starting point of spatial analysis (Liang et al., 2018). The basic formula of SDM model is as follows:

$$
\begin{aligned}
& \ln Y_{i, t}=\beta_{0}+\rho W \ln Y_{i, t}+\beta_{1} \operatorname{lnhum}{ }_{i, t}+\beta_{2} \operatorname{In} p o I_{i, t} \\
& +\beta_{3} \ln \text { fin }_{i, t}+\beta_{4} \ln p o p_{i, t}+\beta_{5} \ln i n n o o_{i, t}+\beta_{6} \ln P g d p_{i, t} \\
& +\theta_{1} W \operatorname{lnedu}_{i, t}+\theta_{2} W \ln p o l_{i, t}+\theta_{3} W \ln \text { fin }_{i, t} \\
& +\theta_{4} W \ln \text { pop }_{i, t}+\theta_{5} W \ln _{\text {inno }}{ }_{i, t}+\theta_{6} W \ln P g d p_{i, t}+\varepsilon_{i, t}
\end{aligned}
$$

There will be only one-way spatial correlation between adjacent regions when there is no spatial interaction in SDM model, that is, SDM model will degenerate into SAR model when $\theta$ is 0 . The SAR model is as follows:

$$
\begin{aligned}
\operatorname{InCap}_{i, t}= & \beta_{0}+\rho W \ln \operatorname{Cap}_{i, t}+\beta_{1} \operatorname{lnhum}{ }_{i, t}+\beta_{2} \operatorname{In} p o I_{i, t} \\
& +\beta_{3} \ln \operatorname{fin}_{i, t}+\beta_{4} \operatorname{Ininno} o_{i, t}+\beta_{5} \operatorname{In} P g d p_{i, t}+\varepsilon_{i, t}
\end{aligned}
$$

SDM model will degenerate to SEM model when $\theta+\rho \beta=0$. The expression of SEM model is as follows:

$$
\begin{aligned}
\operatorname{InCap}_{i, t}= & \beta_{0}+\beta_{1} \operatorname{Inhum}_{i, t}+\beta_{2} \operatorname{In} p o I_{i, t}+\beta_{3} \operatorname{In} f i n_{i, t} \\
& +\beta_{4} \ln p o p_{i, t}+\beta_{5} \operatorname{In} \operatorname{Inno}_{i, t}+\beta_{6} \operatorname{In} P g d p_{i, t}+\mu_{i, t} \\
\mu_{i, t}= & \lambda W \mu_{i, t}+\varepsilon_{i, t}
\end{aligned}
$$

SDM model will degenerate into traditional OLS model when the coefficients of spatial items in SDM model are all 0 :

$$
\begin{aligned}
& \operatorname{InCap}{ }_{i, t}=\beta_{0}+\rho W \ln \operatorname{Cap}_{i, t}+\beta_{1} \operatorname{lnhum}{ }_{i, t}+\beta_{2} \ln p o I_{i, t} \\
& +\beta_{3} \ln \text { fin }_{i, t}+\beta_{4} \ln \operatorname{pop}_{i, t}+\beta_{5} \ln \operatorname{inno}_{i, t}+\beta_{6} \ln \operatorname{lngdp}\left(p_{i, t}+\varepsilon_{i, t}\right.
\end{aligned}
$$

Among Equations (1)-(6), CAP represents the vector of the interpreted variable, $\mathrm{i}$ and $\mathrm{t}$ represent the region and year respectively. $\rho$ is the spatial autoregressive coefficient, $\mathrm{Xi}$ is the explanatory variable vector, $\alpha_{i}$ is the constant term, $\beta$ and $\theta$ are the parameters to be estimated, $\varepsilon$ is the residual 
term, and $\rho W Y_{i}$ is the spatial lag term. Hum is rural human capital, pol is industrial pollution, fin is rural informal finance, pop is population, inno is innovation level, pgdp is rural economic development level.

The explanation of the variable of agricultural non-point source pollution (CAP). Agricultural non-point source pollution mainly refers to the pollution caused by the total nitrogen and phosphorus produced in the process of agricultural production through farmland drainage and underground infiltration. In this paper, the non-point source pollution mainly includes livestock and poultry breeding, aquaculture, agricultural waste, domestic sewage, fertilizer application. This paper uses the inventory method to estimate the load of agricultural non-point source pollution. The values of pollutant production coefficient and emission coefficient of relevant indicators in this paper mainly refer to other scholar (Wang et al., 2011) and the first national pollution source census agricultural source coefficient manual.

In this paper, the core explanatory variable is rural human capital (hum), drawing lessons from Wen et al. (2018) and Gao (2018). The accounting method is $\mid E=\sum_{e i, t} / L_{i, t} . e_{i, t}$ is the corresponding length of schooling, $L_{i, t}$ is the rural population over 6 years old in each region. It sets the length of schooling for illiterate and semi illiterate as one year, primary school as six years, junior high school as nine years, senior high school and secondary school as twelve years, junior college and above as 15.5 years to measure the level of human capital in various regions.

Control variable: The level of economic development (Pgdp). The level of economic development is expressed by the per capita level of rural economic development. The level of economic development has an impact on residents' environmental awareness (Horan, 2001), and its impact on agricultural non-point source pollution cannot be underestimated.

Scientific and technological innovation (inno). Scientific and technological innovation can control agricultural nonpoint source pollution by enhancing the efficiency of agricultural production and strengthening green innovation, which can be measured by comprehensive weighted number of patent authorization.

Population size (POP). The increase of population can cause the increase of resource consumption, which is measured by the number of rural population in unit cultivated land area.

Rural informal finance (fin). Informal finance develops rapidly in rural areas when the formal financial supply in rural areas is seriously insufficient, which provides favorable financial support for the development of rural society and economy. According to the practice of Hu et al. (2016), this paper uses the proportion of the sum of farmers' self raised funds and other funds from the fixed assets investment of farmers in various provinces and cities in the added value of agricultural GDP to characterize it.

Industrial pollution (Pol). Because of the mobility of pollutants, the environment of agricultural operation and production is easily affected by industrial pollution, thus aggravating agricultural non-point source pollution.

$W$ is the spatial weight matrix, which mainly includes geographic feature spatial matrix, economic distance matrix, human capital matrix, etc. The geographic feature spatial matrix mainly includes the adjacency matrix and the geographical distance matrix. The former is $(0,1)$ matrix, and the latter is to use the geographical distance between provinces and cities to measure the distance between them, generally expressed by the reciprocal of the linear Euclidean distance between provinces and capitals. This paper takes geographic distance matrix as spatial matrix and spatial adjacency matrix as robustness test.

\subsection{Data source}

Data of provinces and cities (not including Hong Kong, Macao, Taiwan and Tibet) from 2004 to 2017 are adopted, which mainly come from China Statistical Yearbook, China Population Statistical Yearbook, China Yearbook of Fixedasset Investment and China Rural Statistical Yearbook.

\section{Spatial correlation test}

The precondition of adopting spatial panel data model is that the variables have spatial correlations. In this essay, Moran'l is used to conduct correlation test on the farmland surface pollution indexes. As shown in Table 1, the farmland surface pollution in China from 2004 to 2017 had spatial correlation. The farmland surface pollution within 2004 to 2017 was significant at 1\% significance level and was of positive value, indicating the farmland surface pollution in China has obvious regional correlation. In terms of time tendency, it was generally in volatility within 2004 to 2017, among which Moran'I value was at the peak in 2005 and 2014 and at the valley in 2009 and 2013.

Table 1. Global Autocorrelation Index

\begin{tabular}{cccccc}
\hline Year & Moran's I & $\boldsymbol{P}$ value & Year & Moran's I & $\boldsymbol{P}$ value \\
\hline 2004 & 0.457 & 0.000 & 2011 & 0.439 & 0.000 \\
\hline 2005 & 0.551 & 0.000 & 2012 & 0.452 & 0.000 \\
\hline 2006 & 0.472 & 0.000 & 2013 & 0.412 & 0.000 \\
\hline 2007 & 0.477 & 0.000 & 2014 & 0.517 & 0.000 \\
\hline 2008 & 0.485 & 0.000 & 2015 & 0.517 & 0.000 \\
\hline 2009 & 0.417 & 0.000 & 2016 & 0.498 & 0.000 \\
\hline 2010 & 0.460 & 0.000 & 2017 & 0.480 & 0.000 \\
\hline
\end{tabular}

The global autocorrelation index can test the whole correlation, the spatial correlation of local farmland surface pollution in China cannot be observed from it. In this essay, local moral'l index is adopted to evaluate the spatial correlation between neighboring regions. Moran'l index is used to plot Moran scatter diagram of farmland surface pollution of provinces and cities in China in 2004 and 2017, as shown in Figure 1. In 2004, provinces and cities in the first quadrant include Anhui, Fujian, Chongqing, Gansu, Guangdong, Guangxi, Guizhou, Henan, Hubei, Hunan, Jiangsu, Jiangxi, Shandong, Shanghai and Zhejiang, forming the "high-high" cluster region; provinces and cities in the second quadrant include Hainan, Tianjin, Yunnan, forming the "low-high" cluster region; provinces and cities in the third quadrant include Hebei, Heilongjian, Jilin, Liaoning, Inner Mongolia, Ningxia, Qinghai, Shaanxi, Shanxi and 
Xinjiang, forming the "low-low" cluster region; provinces and cities in the fourth quadrant include Beijing and Sichuan, forming the "high-low" cluster region. Therefore, it could be seen that the farmland surface pollution had great spatial differences between the regions in 2004 and had obvious positive correlation and clustering features.
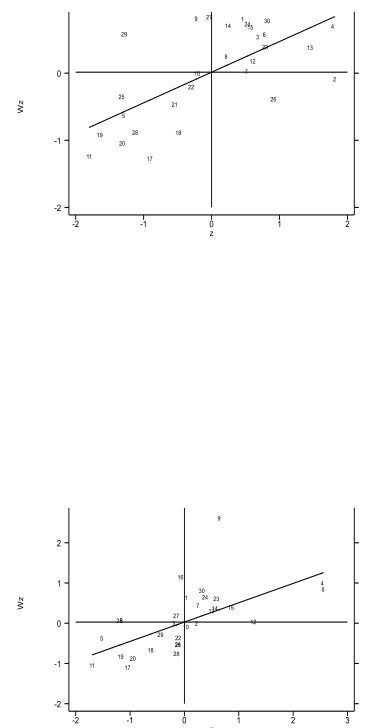

Figure 1. Scatter diagram of local moran'i index in 2004 (left) and 2017 (right)

Note: 1-anhui 2-beijing 3-chongqing 4-fujian 5-gansu 6guangdong 7-guangxi 8-guizhou 9-hainan 10-hebei 11heilongjiang 12-henan 13-hubei 14-hunan 15-jiangsu 16-jiangxi 17-jilin 18-liaoning 19-neimenggu 20-ningxia 21-qinghai 22shaanxi 23-shandong 24-shanghai 25 -shanxi 26 -sichuan 27 tianjin 28-xinjiang 29-yunnan 30-zhejiang

In 2017, provinces and cities in the first quadrant include Anhui, Fujian, Guangdong, Guangxi, Hainan, Hubei, Jiangsu, Shandong, Shanghai, Shanxi and Zhejiang, forming the "high-high" cluster region; provinces and cities in the second quadrant include Jiangxi, forming the "low-high" cluster region; provinces and cities in the third quadrant include Chongqin, Gansu, Heilongjiang, Jilin, Liaoning, Inner Mongolia, Ningxia, Shaanxi, Xinjiang, Yunnan and Qinghai, forming the "low-low" cluster region. Beijing and Henan spanned the first and the fourth quadrants, Guizhou and Sichuan spanned the second and the third quadrants, and Hebei spanned the third and fourth quadrants.

Combining the graphics of 2004 and 2017, it could be seen that farmland surface pollution in China is featured as "high-high" cluster and "low-low" cluster. In 2004, most of the provinces and cities concentrated in the first quadrant, which dropped slightly in 2017; meanwhile, regions in the third and fourth quadrant shifted gradually towards the first and third quadrant, indicating that the comprehensive level of farmland surface pollution in China was polarized.

\section{Spatial panel data analysis}

Before conducting quantitative analysis of the spatial panel data, it is necessary to select and set up the spatial panel model. First, it is to determine whether SDM model has degraded into SAR model by wald test and whether SDM model has degraded into SEM by LR test. The test results as shown in Table 2. The test results of whether spatial Durbin model (SDM) has degraded into spatial auto-regression model (SAR) or spatial error model (SEM) all reject the null hypothesis at $5 \%$ significance, which suggests SDM is suitable. Second, Hausman test is conducted to determine whether fixed effect model or random effect model should be established. The test result is chi2(5)=1393.47, and $P<0.001$, which rejects the null hypothesis at $1 \%$ significance; therefore, fixed effect SDM model is selected.

Fixed effect SDM model is divided into spatial fixed effect, time fixed effect and spatial-time two-way fixed effect. The estimated results are as shown in Table 3. According to AIC and BIC minimum principle, two-way fixed effect model is selected, under which rho value is -0.167 . It is significant at $5 \%$ significance, indicating Chinese farmland surface pollution has significant spatial cluster effect.

It can be seen from Table 3 that the rural human capital in SDM model has significant influences on farmland surface pollution. Since the estimation coefficient could not accurately reflect the effect of the former on the latter, it is decomposed into direct effects, spatial spillover effects and total effect. Meanwhile, the above study is mainly based on spatial adjacent weight matrix, without taking spatial distance into consideration, so, this essay constructs spatial distance weight matrix to test the robustness of the test results. Specific results are shown in Table 4.

As can be seen from Table 4, the direct effect and spatial spillover effect of rural human capital are significantly negative, indicating that rural human capital not only has significant direct effect, but also can cause spatial spillover effect to alleviate farmland surface pollution. The reason is that China has laid great emphasis on the development of rural education for long. Establishment of physics, chemistry and natural sciences has strengthened propaganda of environmental awareness, which is helpful to alleviate farmland surface pollution in livestock breeding and other activities of daily life. Some students who have received education are engaging in agriculture-related work in the countryside, which could alleviate farmland surface pollution from fertilizer application and agricultural solid waste; meanwhile, students who have received higher education have made contribution to green innovative technology and cleaner production, which could facilitate alleviation of farmland surface pollution. The migration and mobility of regional talents can help to enhance the learning and communication of sewage capacity and experience, thus inhibiting farmland surface pollution in adjacent areas. Through further observation, it could be seen that the direct impact coefficient of rural human capital on farmland surface pollution is -0.678 , and the spatial spillover effect is -0.707 , indicating that for every $1 \%$ increase of rural human capital in the region, the farmland surface pollution in this region is reduced by 
$0.678 \%$. The impact of rural human capital on farmland surface pollution in the surrounding area is $0.707 \%$.

Table 2. Inspection results of space panel model

\begin{tabular}{|c|c|c|c|}
\hline Test model & Fixed or random effect test & Whether degenerate into SAR & $\begin{array}{c}\text { Whether degenerate into } \\
\text { SEM }\end{array}$ \\
\hline Test method & Hausman & wald & LR \\
\hline Test value & 1393.47 & 103.90 & 108.04 \\
\hline$P$ value & 0.0000 & 0.0000 & 0.0000 \\
\hline \multicolumn{4}{|c|}{ Table 3. Estimation Results of SDM Model } \\
\hline Variable & Space fixed model & Period fixed effect & $\begin{array}{l}\text { al and moment fixed effects } \\
\text { model }\end{array}$ \\
\hline Inhum & $-0.671^{* * *}(0.1720)$ & $-0.527^{* * *}(0.1300)$ & $-0.618^{* * *}(0.1669)$ \\
\hline Inpol & $-0.0723^{* * *}(0.0179)$ & $0.0149^{*}(0.0084)$ & $-0.0680^{* * *}(0.0174)$ \\
\hline Inpop & $0.878^{* * *}(0.0268)$ & $0.687^{* * *}(0.0210)$ & $0.914^{* * *}(0.0257)$ \\
\hline $\ln p g d p$ & $0.574^{* * *}(0.0295)$ & $0.547^{* * *}(0.0261)$ & $0.621^{* * *}(0.0279)$ \\
\hline Infin & $0.00363(0.0099)$ & $0.0438^{* * *}(0.0146)$ & $0.00266(0.0096)$ \\
\hline$W^{*}$ Inhum & $-0.609^{* *}(0.2899)$ & $0.879^{* * *}(0.2668)$ & $-0.856^{* *}(0.3640)$ \\
\hline W*Inpol & $0.0747^{* *}(0.0296)$ & $-0.0442^{* *}(0.0193)$ & $0.0715^{*}(0.0399)$ \\
\hline$W^{*} \operatorname{Inpop}$ & $-0.0918(0.0660)$ & $-0.0479(0.0564)$ & $0.265^{* * *}(0.0770)$ \\
\hline$W^{*} \ln p g d p$ & $-0.286^{* * *}(0.0437)$ & $-0.366^{* * *}(0.0703)$ & $0.162^{* *}(0.0667)$ \\
\hline$W^{*} \operatorname{lnfin}$ & $0.0292(0.0178)$ & $0.137^{* * *}(0.0391)$ & $0.0601^{* * *}(0.0231)$ \\
\hline Spatial rho & $0.0838(0.0615)$ & $0.0506(0.0699)$ & $-0.167^{* *}(0.0672)$ \\
\hline sigma2_e & $0.00537^{* * *}(0.0004)$ & $0.0222^{* * *}(0.0015)$ & $0.00446^{* * *}(0.0003)$ \\
\hline $\operatorname{adj} . R^{2}$ & 0.8438 & 0.8817 & 0.7741 \\
\hline$A I C$ & -978.4 & -383.0 & -1054.4 \\
\hline$B I C$ & -929.9 & -334.5 & -1005.9 \\
\hline$N$ & 420 & 420 & 420 \\
\hline
\end{tabular}

Note: Standard errors in parentheses, ${ }^{*},{ }^{* *},{ }^{* * *}$ were significant at $10 \%, 5 \%$ and $1 \%$ respectively.

Table 4. Direct Effect and Spatial Spillover Effect of SDM Model

\begin{tabular}{|c|c|c|c|}
\hline Effect category & Variable & Coefficient (Standard errors) & Robust check \\
\hline \multirow{5}{*}{ LR_Direct } & Lnhum & $-0.678^{* * *}(0.1736)$ & $-0.641^{* * *}(0.1645)$ \\
\hline & Lnpol & $-0.0718^{* * *}(0.0172)$ & $-0.0822^{* * *}(0.0171)$ \\
\hline & Lnpop & $0.880^{* * *}(0.0257)$ & $0.912^{* * *}(0.0248)$ \\
\hline & Lnpgdp & $0.571^{* * *}(0.0294)$ & $0.620^{* * *}(0.0276)$ \\
\hline & Lnfin & $0.00430(0.0095)$ & $0.00825(0.0094)$ \\
\hline \multirow{5}{*}{ LR_Indirect } & Lnedu & $-0.707^{* *}(0.2883)$ & $-1.222^{*}(0.6975)$ \\
\hline & Lnpol & $0.0733^{* *}(0.0324)$ & $0.0669(0.0944)$ \\
\hline & Lnpop & $-0.0206(0.0471)$ & $0.268^{* *}(0.1187)$ \\
\hline & Lnpgdp & $-0.256^{* * *}(0.0405)$ & $0.0708(0.0945)$ \\
\hline & Lnfin & $0.0322^{*}(0.0193)$ & $0.121^{* * *}(0.0459)$ \\
\hline \multirow{5}{*}{ LR_Total } & Lnhum & $-1.385^{* * *}(0.2869)$ & $-1.863^{* * *}(0.6975)$ \\
\hline & Lnpol & $0.00149(0.0340)$ & $-0.0153(0.0953)$ \\
\hline & Lnpop & $0.860^{* * *}(0.0535)$ & $1.180^{* * *}(0.1220)$ \\
\hline & Lnpgdp & $0.315^{* * *}(0.0359)$ & $0.690^{* * *}(0.0913)$ \\
\hline & Lnffin & $0.0365^{*}(0.0210)$ & $0.129^{* * *}(0.0477)$ \\
\hline
\end{tabular}

Note: Standard errors in parentheses, ${ }^{*},{ }^{* *},{ }^{* * *}$ were significant at $10 \%, 5 \%$ and $1 \%$ respectively.

Industrial pollution could restrict farmland surface pollution in the region, but it could also intensify farmland surface pollution in the adjacent regions, which goes against the study of Xu et al. (2019). The reason is that at present Chinese industry, especially heavy polluting enterprises are undergoing the process of transmitting from the east towards the middle west and from the city to the rural areas. The government's emphasis on the environmental protection has led industrial companies to be established in regional boundaries. In addition, the sewage water is flowing. With the deepening of industrialization, demands for agricultural resources and agricultural products would cause competition effect. Intensified industrialization in surrounding areas has increased the demands of the area for agricultural resources and agricultural products, which has in turn worsened the farmland surface pollution in this area. 
The density of rural population has increased the farmland surface pollution in the region, whose indirect effect is negative but has not passed the significance test. The estimation coefficient of direct effect of rural population density is the largest and has passed the significance test at $1 \%$ level, suggesting population factor is still the main reason for farmland surface pollution. The reason is that agricultural production and operation requires plenty of manpower and the population, as the active subject of the development of agricultural economy, has provided sufficient laborers for traditional agriculture. Generally, the more people there are, the more frequently they engage in production and consumption, and the more direct and indirect pollutant emissions would be caused. However, rural population density has no significant influences on the farmland surface pollution in the adjacent regions, indicating that no large-scale population mobility could be caused between adjacent regions and therefore, no influences would be caused to on the farmland surface pollution in the neighboring regions. This has partially verified the opinions of $\mathrm{Wu}$ et al. (2017) and Ge et al. (2011).

The direct effect and the spatial spillover effect of rural economic development level on agricultural non-point source pollution have passed the significance test at the level of $1 \%$, but the direct effect estimation coefficient is positive and the spatial spillover effect estimation coefficient is negative. The reason is that continuous increase of the level of economic development has affected to some degree the farmers' behaviors, who increase application amount of fertilizer and pesticide in agricultural production, which has destroyed the environment to some degree. Meanwhile, small-scale agricultural production modes also intensify the difficulty of governing agricultural contamination. When the economy in the adjacent regions develops to a higher degree, it would consciously increase investment in environmental pollution control in the region while uniting the adjacent regions in governing pollution.

The direct and indirect effects of rural informal finance on farmland surface pollution are positive, but the direct effect fails to pass the significance test. The reason is that as the substitution of formal finance, rural informal finance is still in disorder at the present, and there are still poor guidance and overlapping investment. Since the financial controlling authority lacks regulatory basis, informal financial funds flow into polluting agricultural production, which has aggravated farmland surface pollution.

In addition, robustness test has shown that though the sizes of the estimation coefficients vary, there is no large change, so the results are robust and reliable.

\section{Conclusion and countermeasures}

With gradual implementation of the rural revitalization strategy, all the provinces and cities have increased the input of rural human capital so as to improve the human capital level of rural residents in the region. This essay studies the flow of rural human capital factors between the regions and whether the farmland surface pollution could be improved through spatial spillover effects and measure its direct effects and spatial spillover effects. Based on the panel data of 30 provinces and cities in China (not including Hong Kong, Macao, Taiwan and Tibet) from 2004 to 2017, this essay conducts empirical analysis of the influences of rural human capital on farmland surface pollution by spatial panel data model. The research finds that:

(1) The farmland surface pollution between different regions has significant spatial correlation, the farmland surface pollution between the regions does not exist independently, the Moran'l indexes of the farmland surface pollution of the years in China are all significantly positive and the correlation shows volatility. Therefore, when making policies, relevant governmental departments should take full consideration of the conditions as well as the governance of farmland surface pollution of their regions and the adjacent regions, strengthen communication and cooperation of the factors between the regions, and alleviate jointly the farmland surface pollution in the regions, which is helpful to improve the overall level of farmland surface pollution in China.

(2) The direct effect and spatial spillover effect of rural human capital on farmland surface pollution are significantly negative, indicating that rural human capital not only can inhibit farmland surface pollution in the region effectively, but also can help to reduce the farmland surface pollution in the adjacent areas. The revelation of this conclusion is that, as an important power of farmland surface pollution control, flow of rural human capital between the regions has significant spatial spillover effect. Therefore, it is necessary to strengthen cooperation in rural education between the regions, break spatial barriers between the regions, accelerate the development of regional integration and reinforce cooperation in green and clean technologies so as to achieve green development of agriculture.

\section{References}

Bechmann M., Deelstra J., Stålnacke P., Eggestad H.O., Øygarden L. and Pengerud A. (2008), Monitoring catch scale agricultural policy in Norway: policy instruments, implementation of measurement methods and trends in nutrition and division losses, Environmental Science \& Policy, 11(2), 102-114.

Faiza J., Rizwan A. and Muhammad A.A. (2018). Design, fabrication and evaluation of rotary hot-air dryer for the value addition of fruit waste, Earth Sciences Pakistan, 2(2), 7-11.

Fikriah F., Kamaruzzaman Y., Mohd F.M. and Azman A. (2019), Assessment of trace metals using chemometric analysis in Kuantan River, East Coast Malaysia, Journal Clean WAS, 3(2), $1-4$.

Gao X., Li G.C. and Wei S.J. (2018), Agricultural products trade opening, agricultural growth and agricultural environment, Journal of Huazhong Agricultural University (Social Sciences Edition), (04), 54-60 + 168.

Ge J.H. and Zhou S.D. (2011), Analysis of economic factors affecting agricultural non-point source pollution based on data of Jiangsu Province from 1978 to 2009, Chinese Rural Economy, (5), 72-81.

Horan R.D. (2001), Differences in social and public risk perceptions and conflicting impacts on point/nonpoint 
trading ratios, American Journal of Agricultural Economics, 83(4), 934-941.

Hu Z.Y., Ma W.L. and Liu Y.W. (2016), Analysis of the impact of rural informal financial development on regional farmers' income differences, Statistics \& Decision, (16), 86-89.

Humaira G. and Saima N. (2018) Heavy metal uptake from contaminated water using carbon nanotubes: A review, Environmental Contaminants Reviews, 1(2), 4-8.

Lai S.Y., Du P.F. and Chen J.N. (2004), Assessment method of nonpoint source pollution based on unit analysis, Journal of Tsinghua University (Science and Technology), 44(9), 11841187.

Liang W.J., Jiang H., Liao W.Y. and Qin M. (2018), Spatial interaction effect of agricultural non-point source pollution and agricultural economic growth, Jianghuai Tribune, (3), 3442.

Lu W. and Wang H. (2008), Role of rural solid waste management in non-point source pollution control of Dianchi lake catchments, China, Frontiers of Environmental Science \& Engineering in China, 2(1), 15-23.

Md. Nazmul A. and Bo-Ching C. (2019), Sustainable water treatment management, Water Conservation and Management, 3(1), 11-13.

Okoli E.A., Agbasi O.E., Akaolisa C.C.Z. and Inyang N.J. (2018), Seismic analysis of the transgressive systems tracts (TSTS) of the Niger Delta, Earth Sciences Malaysia, 2(2), 16-19

Qiu W.W., Zhong Z.B., Yuan C.H. and Li Z.L. (2018) Spatial differences and dynamic evolution of agricultural non-point source pollution emissions in China, Journal of China Agricultural University, 23(1), 152-163.

Sajil Kumar P.J. (2020), Hydrogeochemical and multivariate statistical appraisal of pollution sources in the groundwater of the lower Bhavani River basin in Tamil Nadu, Geology, Ecology, and Landscapes, 4(1), 40-51

Suhaili M.Z. and Samsudin M.D.M. (2018), Utilization of wastewater for corrosion prevention of carbon steel pipe using single chamber microbial fuel cells, Environment \& Ecosystem Science, 2(2), 47-52.

Swodesh R. and Yuvraj D. (2020), A review on various management method of rice blast disease, Malaysian Journal of Sustainable Agriculture, 4(1), 29-33.

Wang X., Li Z.B., Li P. and Zhang L.H. (2011), Current situation of non-point source pollution in Danhanjiang River Basin of Shaanxi Province and control measures, Bulletin of Soil and Water Conservation, 31(6), 186-189.

Wen T., Zhang Z.Y. and Wang D.X. (2018), Research on threshold effect of human capital in rural financial development, China Soft Science, (3), 65-75.

Wu Y.G., Feng K.W. and Li G.C. (2017), Population growth, structural adjustment and agricultural non-point source pollution: An empirical study based on the spatial panel STIRPAT model, Journal of Agrotechnical Economics, (3), 75-87.

Xia Q., Li D. and Zhou H. (2018), Study on the impact of farmers' concurrent employment on agricultural non-point source pollution, China Population, Resources and Environment, 28(12), 131-138.

Xiong Y. and Xu Y.S. (2019), Productivity measurement and influencing factors of environment-friendly agriculture in Sichuan Province based on super efficiency DEA model and spatial panel STIRPAT model, Chinese Journal of EcoAgriculture, (7), 1134-1146.
Xu C.H. and Xue L. (2019), Agricultural industry agglomeration and agricultural non-point source pollution: Based on the perspective of spatial heterogeneity, Finance \& Economics, (8), 82-96.

Xue L., Liao Z.J. and Wang L. (2019), Urbanization and improvement of agricultural non-point source pollution: spatial heterogeneity analysis based on the adjustment of farmers' income structure, Rural Economy, (7), 55-63.

You H. (2016), Impact of urbanization on pollution related agricultural input intensity in Hubei, China, Economic Indicators, 62, 249-258. 